L. Edwards, ${ }^{1}$ M. E. Fitzpatrick, ${ }^{2}$ P. E. Irving, ${ }^{3}$ I. Sinclair, ${ }^{4}$ X. Zhang, ${ }^{5}$ and D. Yapp ${ }^{6}$

\title{
An Integrated Approach to the Determination and Consequences of Residual Stress on the Fatigue Performance of Welded Aircraft Structures
}

\begin{abstract}
Although residual stress in welded structures and components has long been known to have an effect on their fatigue performance, access to reliable, spatially accurate residual stress field data has been limited. Recent advances in neutron and synchrotron X-ray diffraction allow a far more detailed picture of weld residual stress fields to be obtained that permits the development and use of predictive models that can be used for accurate design against fatigue in aircraft structures. This paper describes a fully integrated study of the three-dimensional residual stress distribution accompanying state-of-the-art fusion welds in 2024-T4 aluminum alloy, and how it is affected by subsequent machining and service loading. A particular feature of this work has been the development of techniques allowing the nondestructive evaluation of the residual stress field in the full range of specimens used to provide the design data required for welded aircraft structures and the integration of this information into all aspects of damage tolerant design.
\end{abstract}

KEYWORDS: residual stresses, fatigue, damage tolerance, structural integrity, welded aircraft structures

\section{Introduction}

Research into cost saving of aircraft metallic members and components is a continuous process in the aerospace industries. Weight saving through design modification of aircraft is being undertaken to support cost reduction programs and to face the challenge of 21 st century mass air transportation [1]. Welding instead of mechanical fastening has been identified as one of the major tools for cost reduction, in terms of weight reduction and by production cost saving through substitution of assemblies and built-up structures by formation of an integral structure. However, unlike mechanical fastening, welding leads to

- An integral structure with a single load path construction.

- Creation of microstructure near the fusion and heat affected zone (HAZ) with changed grain structure and strength.

- Formation of potential sources of initiating defects not present in the wrought alloy.

- Creation of local and global residual stress fields.

All these factors, in particular the creation of a variable residual stress field across the weld, would have a profound influence on the fatigue life of the welded metallic members and components. The civil aircraft design specification demands damage tolerance characteristics in safety critical parts. Therefore, before implementation of such process change it is necessary to establish the fatigue crack growth behavior under the influence of the variable distribution of residual stress that exists following welding. The relationship between the fatigue crack growth in the welded microstructure and the distribution of the residual stress field is the most essential input for the damage-tolerant, fail-safe design of the safety critical components [2].

\footnotetext{
Manuscript received January 7, 2005; accepted for publication August 24, 2005.

${ }^{1}$ Professor of Structural Integrity, Dept of Materials Engineering, Open University, Milton Keynes, UK, MK7 6AA.

${ }^{2}$ Senior Lecturer, Dept of Materials Engineering, Open University, Milton Keynes, UK, MK7 6AA.

${ }^{3}$ Professor of Damage Tolerance, School of Industrial and Manufacturing Sciences, Cranfield University, Cranfield, Bedfordshire MK43 0AL

${ }^{4}$ Reader, School of Engineering, Southampton University, Southampton, UK, SO17 1BJ.

${ }^{5}$ Senior Lecturer, School of Engineering, Cranfield University, Cranfield, Bedfordshire, UK, MK43 0AL.

${ }^{6}$ Senior Lecturer, School of Industrial and Manufacturing Sciences, Cranfield University, Cranfield, Bedfordshire, UK, MK43 OAL.
} 


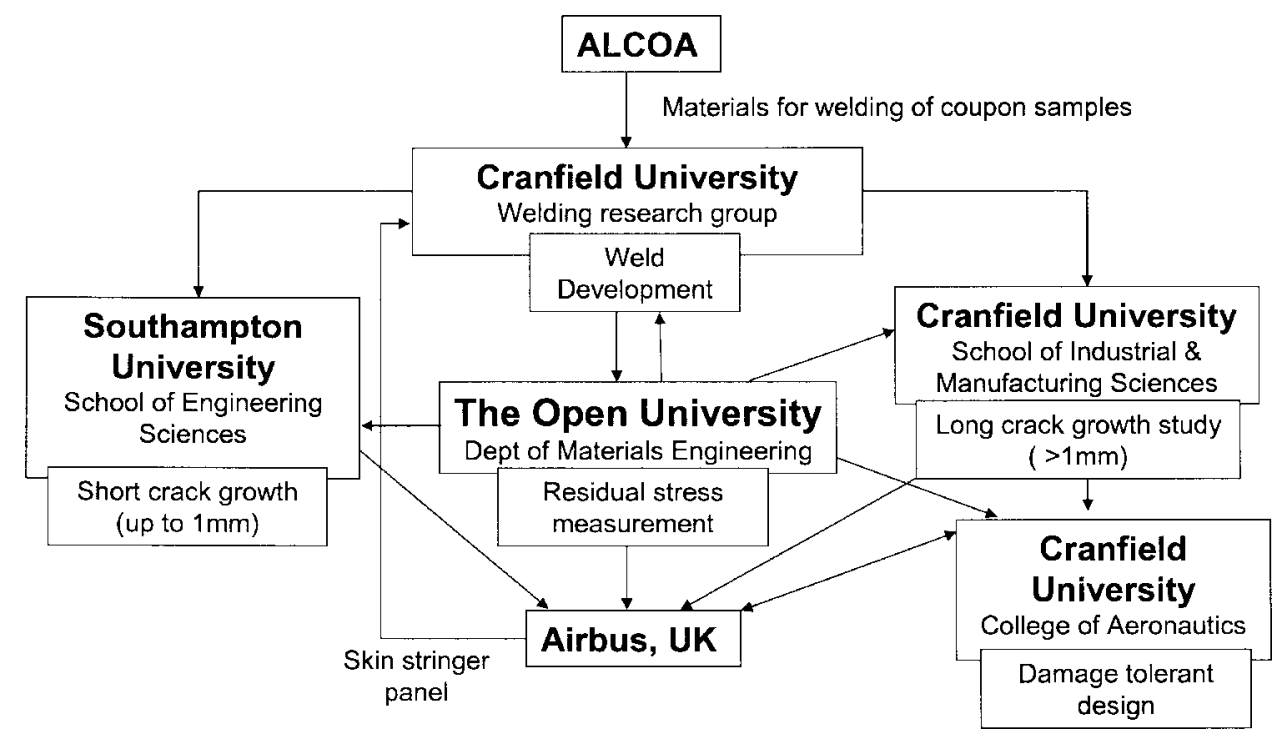

FIG. 1-WELDES project partners and structure.

This paper describes the work of an integrated program, WELDES (weld processing design and durability of welded aircraft assemblies), on the determination and consequences of residual stress on the fatigue performance of welded aircraft structures. The breadth of partners and their main functions are shown in Fig. 1.

The factors controlling fatigue initiation and crack growth in welds are relatively well understood, and the importance of residual stress, HAZ hardness, and microstructure is well known. However, access to reliable, spatially accurate residual stress field data has previously been limited. The development of dedicated neutron and synchrotron X-ray diffraction techniques for the measurement of residual stress has opened up the possibility of acquiring high quality, accurate data which can be used reliably in predictive structural integrity models. However, acquisition of high quality, reliable residual stress data is of optimum use only if it is used to influence both process design and subsequent damage-tolerance data collection and use. This latter point is particularly important, as when one is dealing with residual stress fields, similitude no longer automatically exists between laboratory fracture-mechanics specimens and fabricated components and structures.

Thus, in the present program a fully integrated study has been undertaken of the full residual stress distribution associated with state-of-the-art fusion welds in 2024-T4 and 7150-T651 aluminium alloys, and how they are affected by subsequent machining and service loading. A particular feature of this work has been the development of techniques allowing the nondestructive evaluation of the residual stress field in the full range of specimens used to provide the design data required for welded aircraft structures. This has included small bend specimens used to study initiation and short fatigue crack growth, middle tension $\mathrm{M}(\mathrm{T})$ and compact tension CT specimens used to study long fatigue crack growth, and large integral welded double stringer/skin mockups used to investigate the likely failure mode of welded wing-skin assemblies.

The resulting residual stress data have been combined with relevant microstructural data in the fatigue modeling process. Initiation behavior has been studied using replica techniques to monitor the initiation and growth of cracks from interdendritic pores in the weld HAZ. Initiation of small fatigue cracks occurred virtually from the first cycle at defects in the microstructure and thus models for the growth and linkage of the microcracks, including the role of residual stress, were developed and fatigue initiation behavior (defined as the life to a crack of $1 \mathrm{~mm}$ ) has been accurately calculated from knowledge of intrinsic crack growth rates and HAZ characteristics. Factors controlling macroscopic fatigue growth rates have been investigated using constant $\Delta \mathrm{K}$ tests. The changes in growth rate as the cracks cross the weld have been determined and related to the changes in the residual stress field, hardness, and microstructure within the HAZ. Large-scale skin-stringer mockups have been manufactured and fatigue tested and the implications of the results of the program have been assessed. Both 2024-T4 (lower wing skin) and 7150-T651 (upper wing skin) candidate welds have been studied but only the 2024-T4 work will be described here. 


\section{Weld Processes Studied}

The processes studied in this work were metal inert gas (MIG) welding and variable polarity plasma arc (VPPA) welding. Although MIG welding has been in extensive use for various defence and space research application for many years, because of flexibility and low cost, its application has been restricted in the civil aviation industry, as the high strength heat treated $2 \mathrm{XXX}$ and $7 \mathrm{XXX}$ aluminium alloys used were regarded as unweldable via this process [3].

2024-T4 alloy is a widely known $\mathrm{Al}-\mathrm{Cu}-\mathrm{Mg}$ alloy used extensively in aircraft fuselages and lower wing skin-stringer panels. This is a high-strength, age-hardened alloy and is characterized by its superior damage tolerant characteristics [2]. The alloy has been typically regarded as unweldable because of its compositional range whereby it is prone to hot cracking. Recent advances in welding technology and the use of 2319 filler wire, however, have made it possible to weld 2024-T4 to aviation standard [4].

The dominant cause of generation of residual stress in a weld is the unequal expansion and contraction of the weld metal and the surrounding heat affected zone. The fusion welding process causes intense local heating in the weld metal region and the heat is conducted into the surrounding metal. At this high temperature the metal yields under compression due to the cooler surrounding material. During cooling, uneven contraction between the yielded and nonyielded region gives rise to tensile residual stress along the welding direction.

VPPA welding is a more recently developed process. It has been used for a number of critical applications like the space shuttle external fuel tank [5], and also in structural welding of the international space station by the United States of America's National Aeronautics and Space Administration (NASA) where the weld joint has to withstand the harshest external atmospheric condition [6]. The process is much favored because of its capability to weld relatively thick sections in a single pass, and also for the relatively low distortion of the welded parts that allows for high dimensional accuracy after further machining.

The application of either of these processes in safety critical components in civil aviation, however, requires complete understanding of fatigue crack growth characteristics under the changed microstructure and residual stress field. This would form an important design input for safety critical structures to exhibit damage-tolerant, fail-safe characteristics [2].

Any subsequent machining of the welded component is likely to change the residual stresses within it. As the fracture mechanics specimens that are used to measure material fatigue crack propagation characteristics are, by necessity, smaller than the welded structures they are intended to represent, they also contain significantly different residual stress profiles. Thus, the nondestructive evaluation of the residual stress fields in the full range of specimens used to provide the design data required for welded aircraft structures is essential if fully representative damage tolerance data is to be obtained.

\section{Weld Processes Development}

The MIG process forms an arc between a filler wire and parent plate. VPPA uses a nonconsumable tungsten electrode, and can be used with filler wire or without (autogenous welding). These processes were used to make butt welds in flat coupons, and to weld skin-stringer panels in 2024-T4.

The welded coupons were then used for detailed evaluation of microstructure, tensile, and small-scale fatigue properties, and residual stress evaluation. Large skin-stringer panels were subsequently designed, fabricated, and manufactured, and their residual stress profiles were non-destructively evaluated before full-scale fatigue testing. The material used was $2024-\mathrm{T} 4 \mathrm{Al}-4.4 \% \mathrm{Cu}-1.5 \% \mathrm{Mg}$ T351 supplied as $12.7 \mathrm{~mm}$ thick plate. The MIG filler metal was $5039 \mathrm{Al}-2.8 \% \mathrm{Zn}-3.8 \% \mathrm{Mg}$. In general, fusion welding of aluminium alloys is regarded as difficult since they are susceptible to porosity because of the evolution of hydrogen during welding, and also to solidification cracking because of the wide solidification range in some alloys. The MIG welds were produced in the flat position (plate horizontal) using a two-pass procedure (Fig. 2). The VPPA welds were produced by welding vertically up (plate vertical) in a single pass.

The VPPA process produces a "keyhole"- the plasma pressure generates a cavity completely through the plate to be welded, and the molten weld metal flows round the keyhole to form the weld. The welded coupons were $240 \mathrm{~mm}$ by $500 \mathrm{~mm}$ by $12.7 \mathrm{~mm}$. For both MIG and VPPA, good quality welds were produced, with an absence of gross defects, either large pores, or large solidification cracks. However, the MIG welds did contain a high density of small $(50-200 \mu \mathrm{m})$ gas pores, and small $(20-50 \mu \mathrm{m})$ interden- 


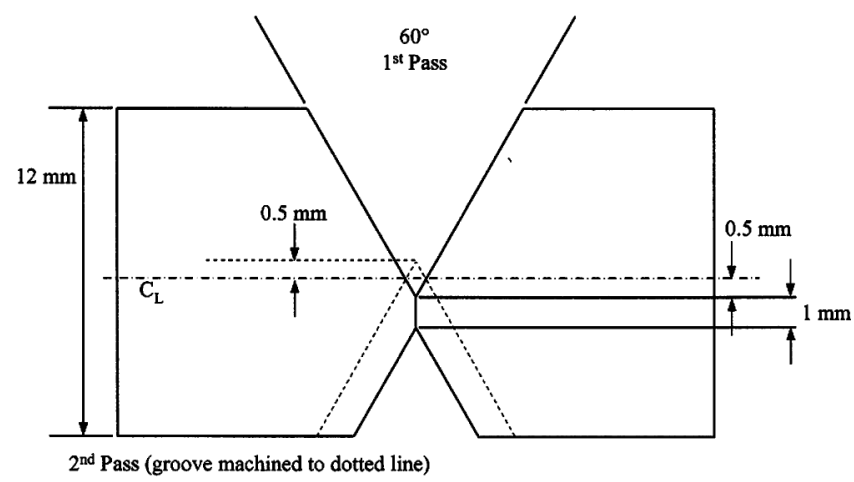

FIG. 2-Schematic showing cross section of plate preparation for MIG Welding.

dritic defects. In contrast, the VPPA welds were essentially defect-free. There were some interdendritic defects in the weld metal on micro-examination, but these were less than $20 \mu \mathrm{m}$ in length, smaller, in fact, than the intermetallics in the parent material.

This is a remarkable outcome for arc welding of aluminium. It is thought that the presence of the keyhole and the flow of weld metal round the keyhole are responsible for this result. The MIG welding could be performed at relatively low heat input, $0.93 \mathrm{~kJ} / \mathrm{mm}$, whereas for the VPPA welding the heat input was higher at $4 \mathrm{~kJ} / \mathrm{mm}$. This results in a slower thermal cycle for VPPA compared to MIG, and this produces a wider and softer heat affected zone (HAZ) in the VPPA welds compared to the MIG welds.

Skin-stringer panels were manufactured using the VPPA process only. There were a number of differences in the weld when compared to the flat plate coupons. In particular, as the effective heat sink is quite asymmetric, owing to the proximity of the weld center line to the doubler, the HAZ width differed on either side of the weld. The final $1.2 \mathrm{~m}$ long as-welded and machined skin stringer panel is shown in Fig. 3. The weld is located approximately at one third of the height of the stringer. A detailed description of the geometry is given later in this paper.

\section{Residual Stress Measurement}

Residual stresses are difficult to account for in structural integrity calculations for several reasons: they are introduced and evolve throughout a range of production stages; they affect fatigue crack initiation and growth rates; they may evolve as a consequence of in-service loading; and perhaps most importantly, residual stresses have been traditionally difficult to determine reliably and accurately. These problems become acute when dealing with stress fields arising from welding. Residual stresses are critically dependent upon welding parameters, heat input, number of weld passes, and the properties of the material(s) being welded. Accurate determination of residual stresses is not simple. Methods such as hole drilling are destructive and reliable methods for the determination of residual stresses deep within structures and components have only recently become available.

Thus, a robust methodology was developed for determining nondestructively the residual stress field in these aluminium alloy welds for aerospace applications using state of the art techniques. The method combines rapid data acquisition from synchrotron X-ray diffraction, coupled with the high penetration of

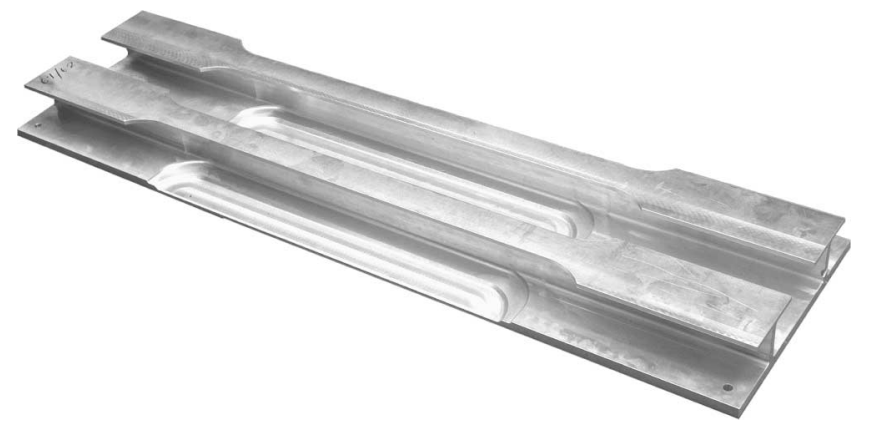

FIG. 3-As-fabricated and machined skin stringer panel. 
TABLE 1-Samples and residual stress measurement technique used.

\begin{tabular}{ccc}
\hline Sample & Dimensions $(\mathrm{mm})$ & Source \\
\hline As -welded & $240 \times 280 \times 12$ & Neutron and synchrotron \\
Machined to $7 \mathrm{~mm}$ & $240 \times 280 \times 7$ & Neutron and synchrotron \\
Short crack coupons & $100 \times 90 \times 7$ & Synchrotron \\
MT coupons & $380 \times 80 \times 7$ & Neutron \\
Skin stringer panels & $1240 \times 350 \times 80$ & Neutron \\
\hline
\end{tabular}

neutron diffraction to build up a profile of the residual stress. The measurement methods employed for a given task depended on the size and scale of both the specimens and the residual stresses present as summarized in Table 1.

As may be seen from Table 1 the main techniques used were:

\section{Neutron Diffraction}

Neutron diffraction is now a well-established method for the measurement of elastic strain in crystalline materials [7]. It has been applied to a wide range of materials and problems, and a draft International Standards Association (ISO) standard for its use is now in circulation [8]. Neutrons have high penetration into most materials, and hence it is possible to make measurements up to several tens of $\mathrm{cm}$ inside structural components so it has the advantage that large specimens can be studied (Fig. 4).

\section{Synchrotron X-ray Diffraction}

Synchrotron X-ray diffraction is a relatively new technique for strain measurement [7]. Using highintensity X-ray beams it is possible to obtain highly detailed strain maps inside components in as little as an hour, much faster than is possible with neutron diffraction. The method has a drawback in that for most samples one strain component cannot be measured in depth, because a grazing incidence of the beam is needed that gives an overly large path length for sensible measurement. As a result, we have developed a method that combines the high speed and resolution of the synchrotron X-ray method with the ability of neutrons to give all strain components [9].

Thus, the precise technique used depended on the size of the specimen. In the small three-point bend specimens of dimensions 80 by 80 by $7 \mathrm{~mm}^{3}$, used to study fatigue crack initiation and crack growth up to $1 \mathrm{~mm}$, the near-surface residual stresses were determined using laboratory and synchrotron X-ray diffraction alone. Conversely, the large skin-stringer panels were measured only using neutron diffraction.

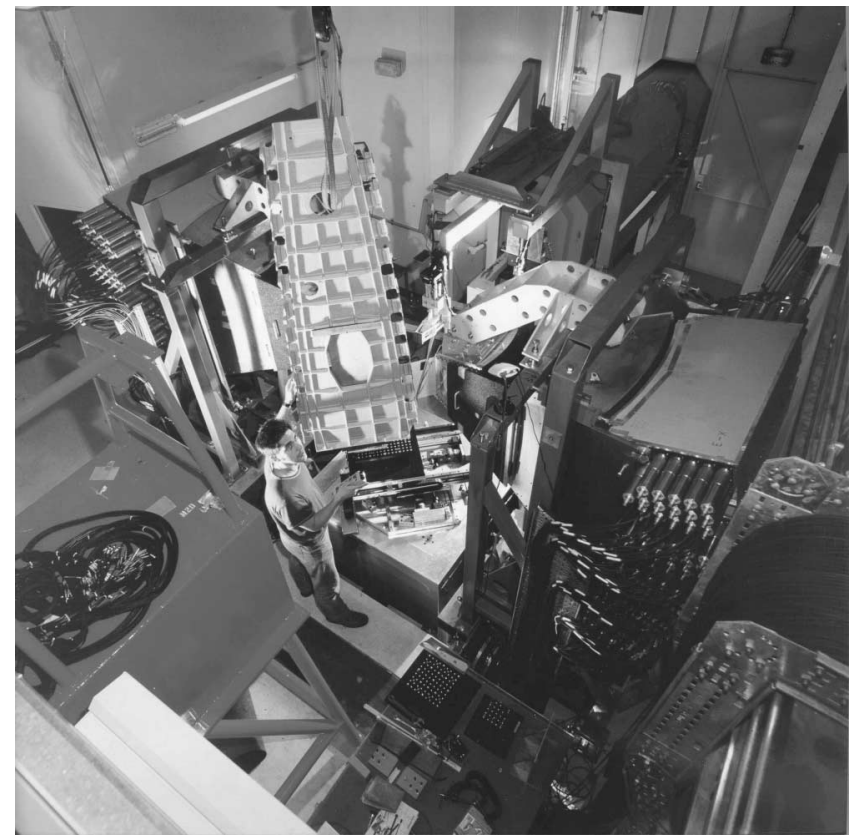

FIG. 4-Installing a large wing rib sample on the ENGIN-X neutron stress diffractometer [10]. 


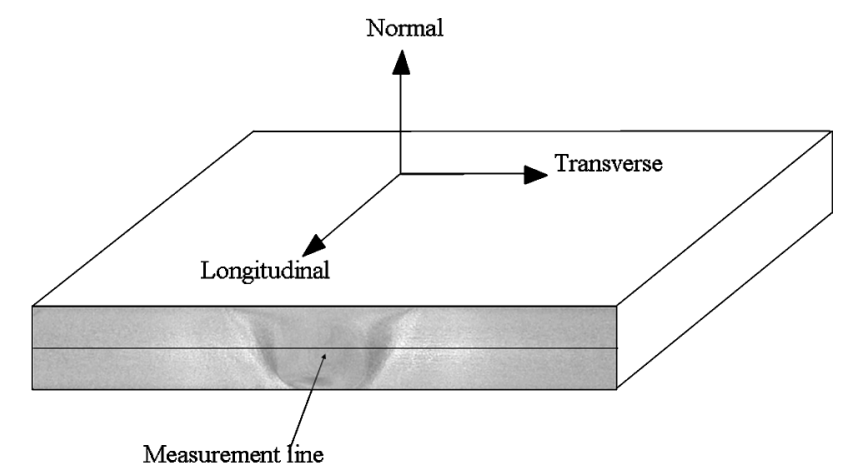

(a)

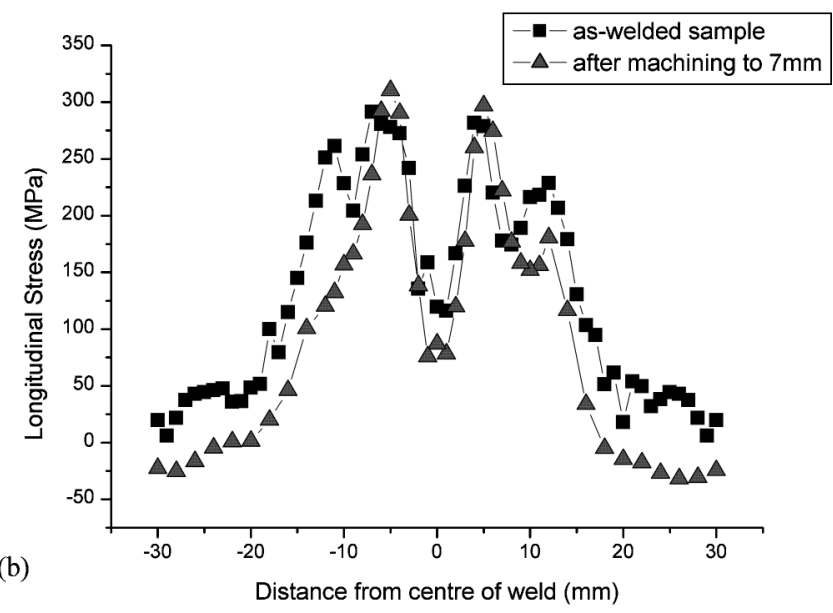

FIG. 5-(a) Schematic showing the measurement geometry in the weld coupons and strain measurement directions and (b) longitudinal residual stresses in a 2024-T4 welded coupon before and after machining the thickness from 12 to $7 \mathrm{~mm}$.

The residual stress profiles in the remaining intermediate size specimens were measured using a novel combination of neutron and synchrotron X-ray diffraction in both the as-welded and machined-tothickness conditions.

\section{Weld Coupon Stresses}

The as-welded coupons were $0.5 \mathrm{~m}$ long, $12 \mathrm{~mm}$ thick, and $186 \mathrm{~mm}$ wide. Typically a section $280 \mathrm{~mm}$ long was cut from this original coupon and the longitudinal, transverse, and normal strains were measured at its center point on a plane perpendicular to the weld. The geometry of the weld and the specific strain directions measured are as schematically shown in Fig. 5(a). On the reasonable assumption that these three directions are principal strain directions, all three stresses were then calculated using Hooke's Law. For brevity, only the longitudinal stresses are presented here. After this measurement the specimen was then machined down to $7 \mathrm{~mm}$ thickness and the stresses were remeasured. Figure 5(b) illustrates the longitudinal stress re-distribution that was found on the center line of a 2024-T4 MIG welded specimen as a result of this mechanical processing. As can be seen from Fig. 5(b), the peak stresses are not changed after machining but the width of the central area containing the tensile residual stresses is slightly reduced. Note that the residual stress directions are related to both the weld direction and plate geometry and these definitions apply to all measurements given in this paper. The error on each of the stress measurements shown in Fig. 5 is of the order of $\pm 10 \mathrm{MPa}$. Unless otherwise plotted on the graph this value may be taken to be the error of all stress measurements reported here.

\section{Typical Residual Stress Results}

Complete cross-sectional mapping of the full stress tensor was carried out for many of the welds and fracture mechanics specimens involved in this study; details of both the methods used and the results 
(a)
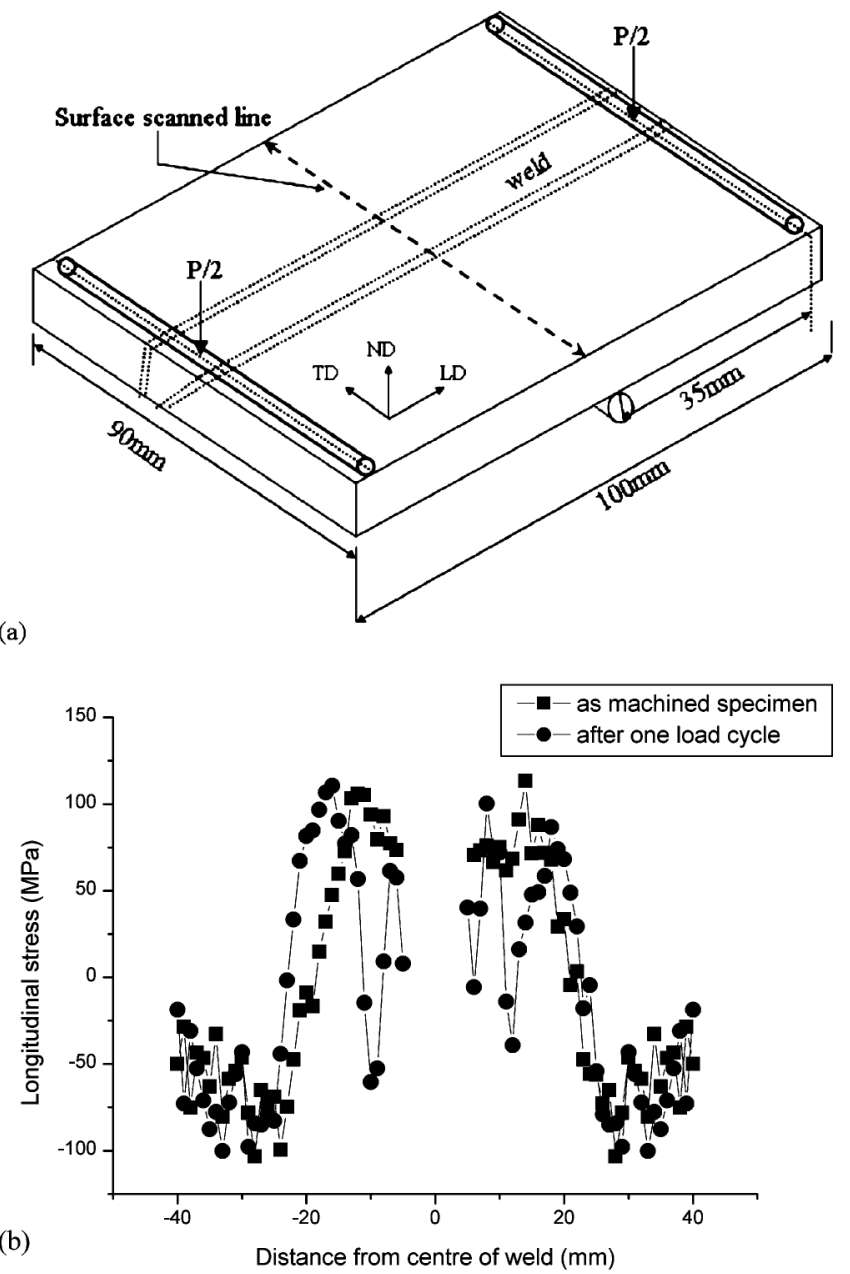

FIG. 6-(a) Schematic figure showing test, weld, and measurement geometry of three point bend small fatigue crack growth specimen. (b) Near-surface longitudinal residual stresses in the 2024-T4 VPPA sample before and after the application of the first load cycle.

obtained are published elsewhere [9,11-16]. Here, for brevity, line measurements of longitudinal stress will be reported. For the small fatigue crack specimen, which is loaded in bending, near-surface measurements will be presented. For all the other specimens, the longitudinal residual stresses across the middle of the specimen perpendicular to the weld will be presented as described in schematic diagrams which accompany each measurement described in this paper.

\section{Small Fatigue Crack Specimens}

The three-point bend small fatigue crack growth specimens had dimensions $80 \mathrm{~mm}$ by $80 \mathrm{~mm}$ by $7 \mathrm{~mm}$ [Fig. 6(a)]. The near-surface residual stresses in both the as-prepared specimens and after the application of the first tensile stress cycle (300 MPa), were determined [17]. As can be seen from the 2024-T4 VPPA results shown in Fig. 6(b), (where the stresses are measured using an effective gage volume covering a depth of $500 \mathrm{~mm}$ centerd at a depth of $650 \mathrm{~mm}$ below the tensile surface) stress redistribution does occur on first loading as relatively high stresses (in this case $300 \mathrm{MPa}$ ) are often used in short fatigue crack growth testing.

\section{Long Fatigue Crack Specimen Stresses}

Long fatigue crack growth propagation rates across the weld were monitored in two specimen types. Most of the testing was performed on 300 by 80 by $7 \mathrm{~mm}$ middle tension $[\mathrm{M}(\mathrm{T})]$ panels. Some comparison testing was also carried out on $7 \mathrm{~mm}$ thick compact-tension (CT) specimens with $W=70 \mathrm{~mm}$. The preparation of the $80 \mathrm{~mm}$ wide $\mathrm{M}(\mathrm{T})$ samples from the $186 \mathrm{~mm}$ wide, $7 \mathrm{~mm}$ thick weld coupons further 


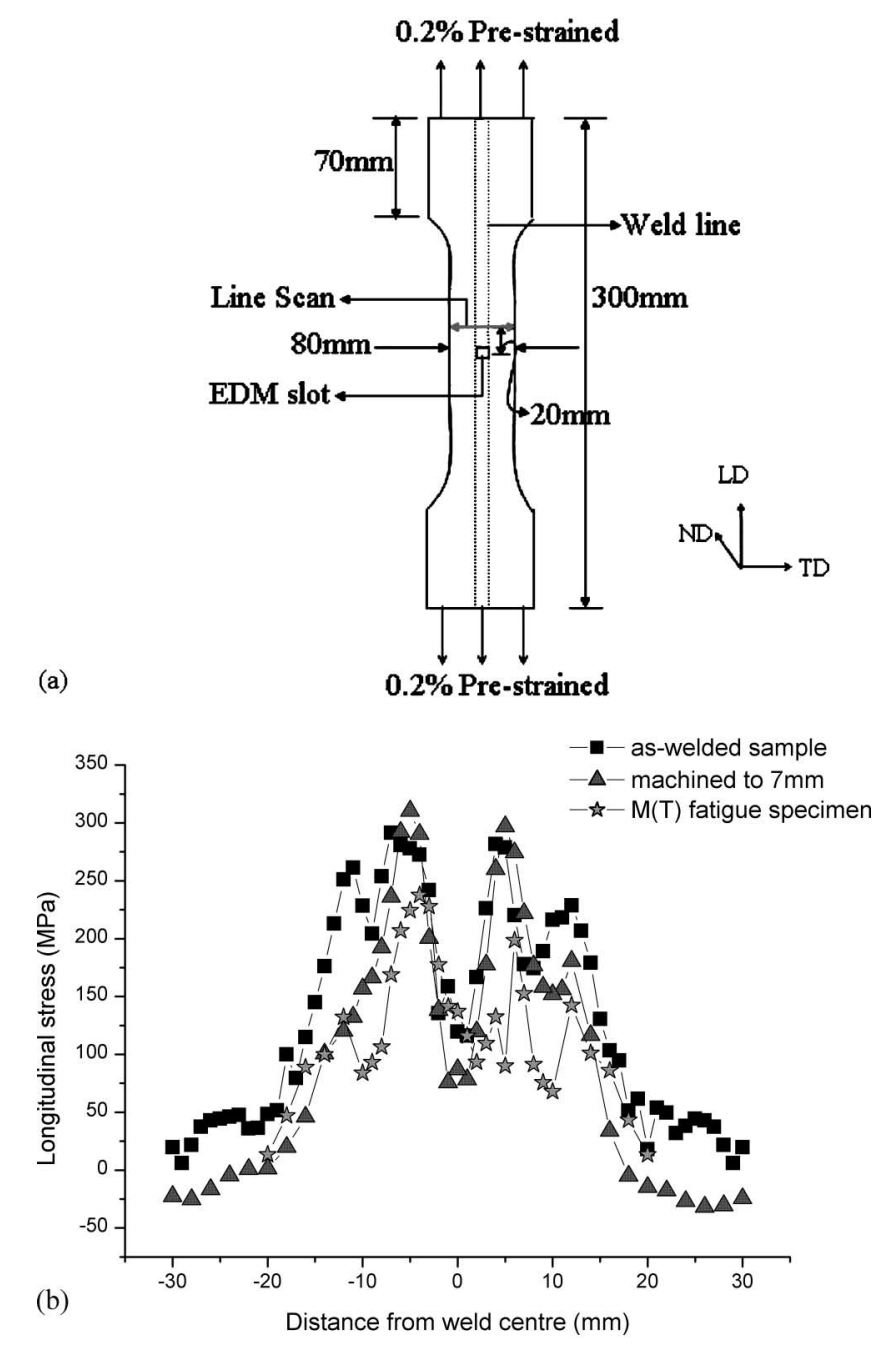

FIG. 7-(a) Schematic of $M(T)$ specimen showing weld and measurement geometry. (b) Longitudinal stresses in 2024-T4 MIG M(T) long fatigue crack growth specimens.

relieved the longitudinal residual stress as can be seen from Fig. 7 which shows the stress evolution in the production of a 2024-T4 M(T) specimen. It can be seen that while reducing the thickness of the original welded plates from 12 to $7 \mathrm{~mm}$ had little effect on the peak longitudinal stresses, reduction of the transverse width of the plates resulted in a drop in peak longitudinal stress of nearly $150 \mathrm{MPa}$. The production of the CT specimens caused an even larger redistribution, caused principally by the introduction of the notch. Figure 8 plots the longitudinal stress in a 2024-T4 MIG CT specimen. It can be seen by comparison of this figure with Fig. 7 that there are significant changes in both the size and shape. The introduction of the notch in the CT specimen has caused the residual stresses to be no longer symmetric with respect to the weld. There is a substantial reduction in the peak tensile longitudinal stress from 225 to $130 \mathrm{MPa}$ and the crack tip now sees a compressive longitudinal stress of $-50 \mathrm{MPa}$.

\section{Skin-Stringer Fatigue Specimen Stresses}

The skin-stringer fatigue specimen, which was designed in this study using the data obtained from the as-welded coupon stresses, is very large $(1240$ by 170 by $77 \mathrm{~mm}$ ) and thus can only be measured using the latest state-of-the-art neutron diffractometers such as the ENGIN-X diffractometer at ISIS pictured in Fig. 4 [10]. The design of this specimen is discussed later in this paper but a schematic figure of the specimen cross section showing the position of the welds is shown in Fig. 9(a). The longitudinal residual stress measured along the web and doubler of the 2024-T4 VPPA skin-stringer fatigue specimen [see schematic Fig. 9(b) for the positions of the two measurement lines] are shown in Fig. 9(c). It can be seen that the longitudinal stress in the web is asymmetric with respect to the weld and the peak stress $(150 \mathrm{MPa})$ occurs 
(a)
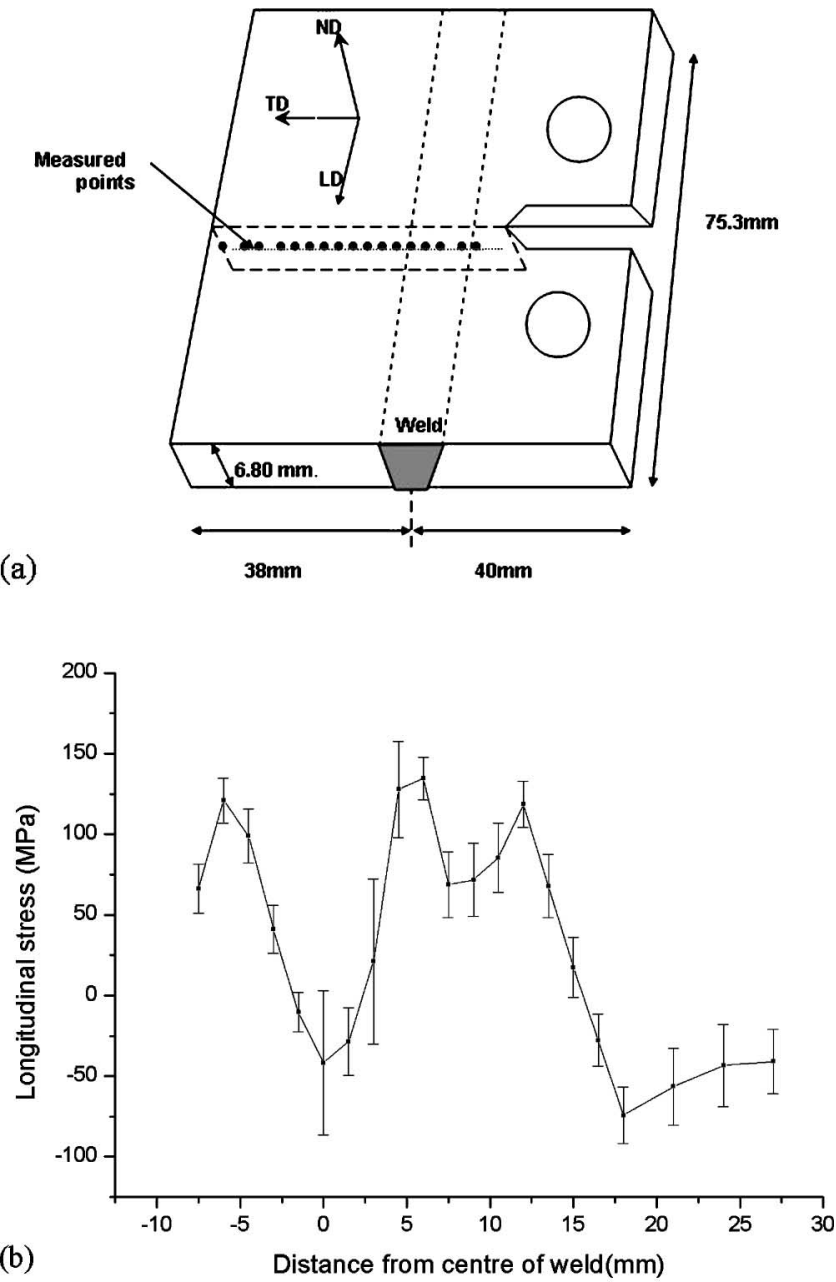

FIG. 8-(a) schematic of specimen showing weld and measurement geometry of 2024-T4 MIG W $=70 \mathrm{~mm}$ CT specimen (b) measured longitudinal residual stress along the crack line.

away from the skin toward the top of the stiffener. On the other side of the stiffener weld, near to the skin, the peak longitudinal stress is lower (100 MPa), a value consistent with that found across the doubler. The lower stresses found on the skin side of the weld are probably the result of lower temperatures being achieved there during welding due to the whole skin acting as a heat sink.

\section{Short Fatigue Crack Initiation and Growth}

The initiation and growth of short fatigue cracks was studied in three-point bend loading (using the 80 by 80 by $7 \mathrm{~mm}^{3}$ sample and loading geometry described in Fig. 6(a), at constant cyclic load amplitudes and a $R$ ratio (minimum stress/maximum stress) of 0.1. Samples were loaded in the longitudinal orientation (i.e., parallel to the weld line), consistent with the final skin-stringer demonstrator structure. Scanning electron microscopy (SEM), transmission electron microscopy (TEM), optical microscopy, hardness mapping, and differential scanning calorimetry were also used to elucidate the local microstructural conditions of the regions in and around the welds (particularly identifying the competition between ageing, overageing, resolutionizing, and reprecipitation occurring across the HAZ).

It was found that several fatigue crack initiation processes may occur within the welds and associated HAZs, each with its own implications for performance/lifing. Fatigue life of the MIG welds was seen to be controlled by fusion zone behavior, determined by the combined effects of interdendritic defect size, crack coalescence, and residual stresses. Quantitative analysis showed that while interdendritic defects in the MIG weld were distinctly smaller than the gas bubbles (up to $\sim 50 \mu \mathrm{m}$ for the interdendritic defects, as opposed to $\sim 200 \mu \mathrm{m}$ for the bubbles), the interdendritic defects were more prominent initiation sites (consistent with their angular morphology and damaging colocation of intermetallic particles at the sharp 
(a)

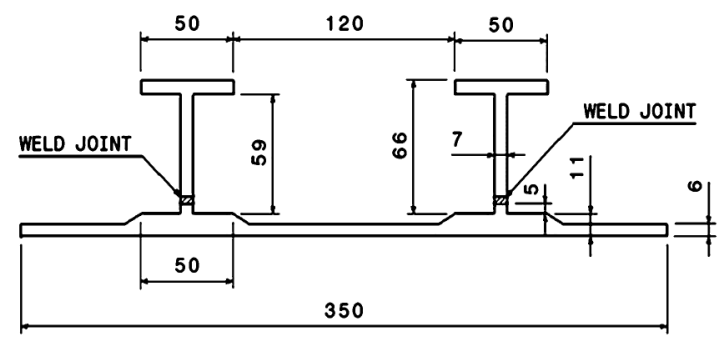

(b)
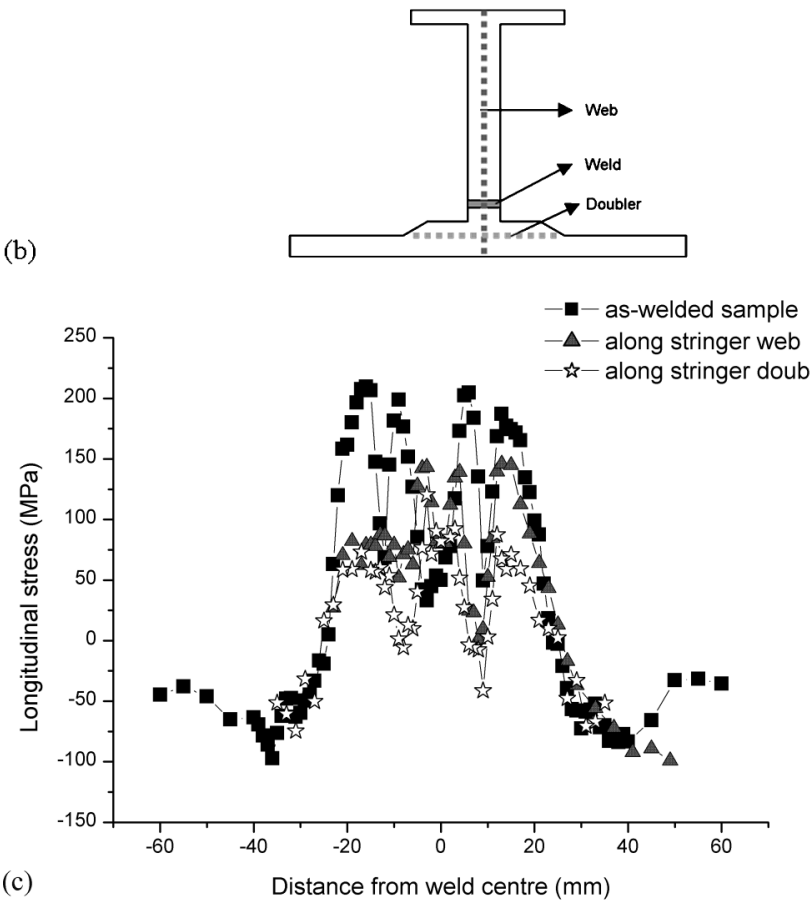

FIG. 9-(a) Cross section of skin stringer design, (b) measurement lines, (c) longitudinal residual stresses in the web and doubler of the 2024-T4 VPPA skin stringer fatigue specimen.

corners formed by neighboring dendrite arms), see Fig. 10. In the VPPA welds, the fusion zone presented a much finer, lower density of crack initiating defects, and although crack initiation was indeed seen in the fusion zone, failure was controlled by cracks forming at the peak residual stress location of the HAZ. Such cracks were associated with the intrinsic defect population of the parent material (intermetallic particle clusters).

Within MIG weld samples it was noted that failure of the weld was dominated by multiple crack formation and coalescence, with no single dominant crack appearing until cracks coalesced right across the fusion zone (a distance of the order of $10 \mathrm{~mm}$ ) and started to propagate into the weld heat affected zone (HAZ), see Fig. 11. In contrast, little influence of crack-crack interactions was seen in failure of the VPPA welds.

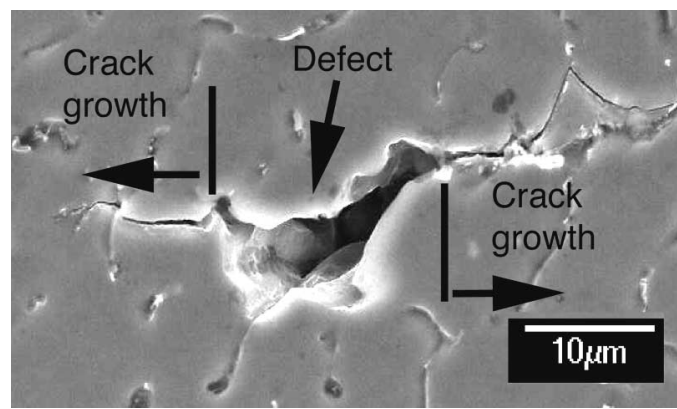

FIG. 10-Typical crack initiation seen at small/acicular interdentric defects of MIG weld fusion zone. 


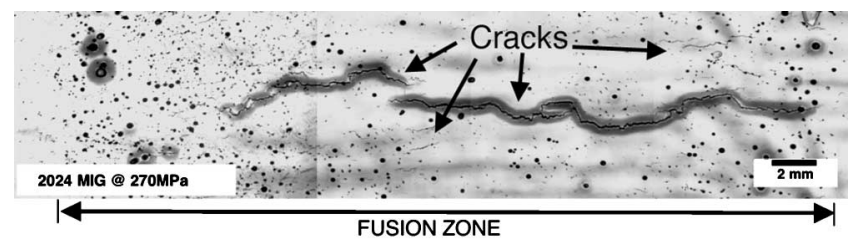

FIG. 11-Multiple crack interaction/coalescence across MIG weld fusion zone.

In the context of fatigue life to $1 \mathrm{~mm}$ total crack length, a micromechanical model has been developed for the MIG fusion zone and VPPA HAZ. The model considers the probability of initiation and the density/distribution of pores (or intermetallic particles) within a given microstructure. A Monte Carlo approach was used to simulate microstructural influence on crack initiation and crack densities. A microstructural model of short crack growth rates was then used [18], considering the local influences of grain size and flow strength on failure. The incidence of crack interactions is considered via a simple geometrical method [19]. The crack growth rate part of the modeling approach was calibrated via "subsized" coupon testing, where small bend bars ( 3 by $1.5 \mathrm{~mm}$ in cross-section, $25 \mathrm{~mm}$ long, see Fig. 12) were taken from specific regions of the welds: at this scale, the samples represented essentially homogeneous material that could be considered residual-stress-free as they were significantly smaller than the wavelength of the measured stress distribution. The influence of residual stress on weld failure was then considered purely in terms of crack closure via a simple closure model (going from a closure-free initial growth to steady-state long crack behavior). Predictions with and without residual stress (RS) effects were made by including the longitudinal residual stress measured at the crack initiation site after the first load cycle. Initiation actually occurred where the longitudinal residual stress was highest in Fig. 7; so the value taken was $100 \mathrm{MPa}$.

Overall it was found that the initiation/short crack fatigue behavior of both the VPPA and MIG welds could be reasonably well predicted, and Fig. 13 shows the prediction for VPPA welded 2024-T4.

\section{Long Fatigue Crack Growth}

Measurements of fatigue crack growth rates at constant load amplitude were performed on samples with three size scales: CT samples with a W dimension of $70 \mathrm{~mm}, \mathrm{M}(\mathrm{T})$ panels $380 \mathrm{~mm}$ long and $80 \mathrm{~mm}$ gage length width with the weld on the center line, and a $1.2 \mathrm{~m}$ long skin-stringer panel with the stringer welded to the skin longitudinally. The three types of samples have been described when reporting their residual stress profiles earlier. Sample thickness in CT and $M(T)$ samples was $7 \mathrm{~mm}$ : this was the skin thickness in the skin-stringer panel. The effects of mean stress, weld process, and alloy type on fatigue crack growth rates were systematically studied. In compact tension (CT) and middle tension $[\mathrm{M}(\mathrm{T})]$ specimens, crack lengths were monitored using a precision dc electrical potential technique. In skinstringer panels an automated video system was used.

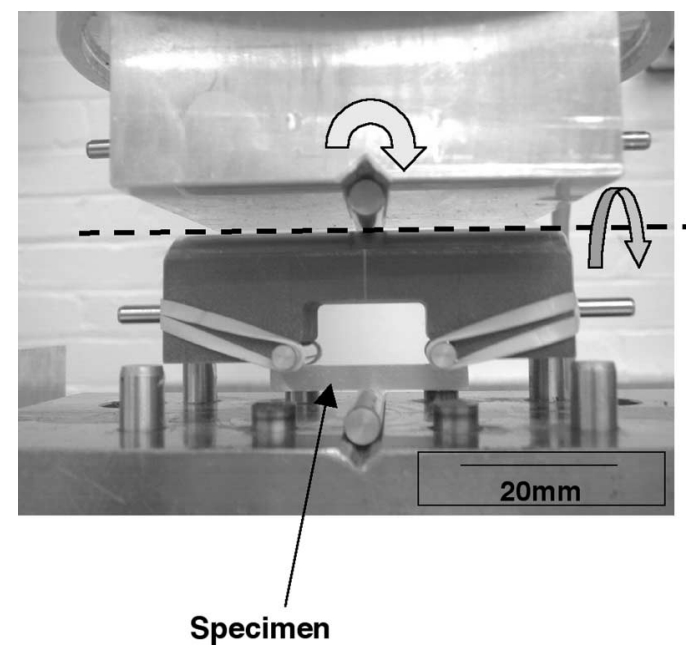

FIG. 12-Subsize fatigue testing, showing test specimen and self-aligning bend fixtures. 


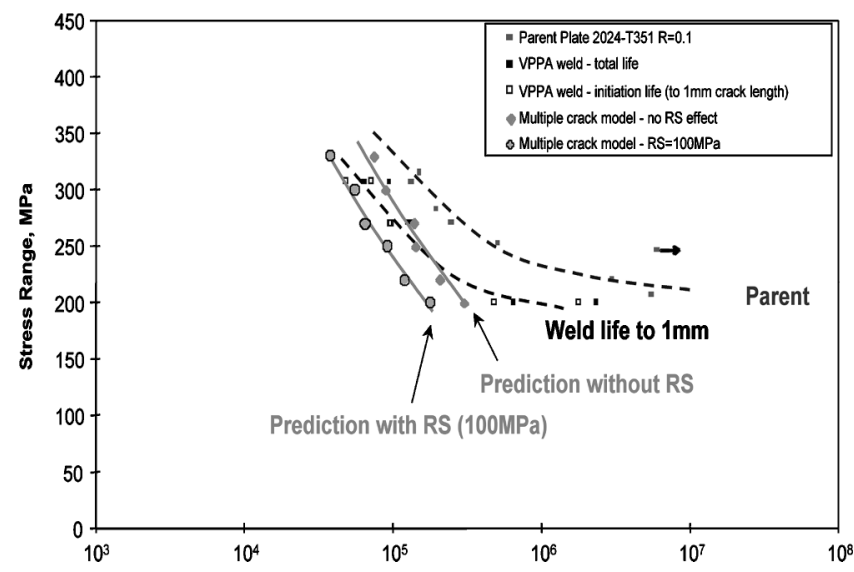

FIG. 13-Comparison of experimental and predicted fatigue lives for VPPA welded 2024-T4: Weld life and predictions are particularly shown for a crack length of $1 \mathrm{~mm}$.

All welds were loaded parallel to their longitudinal axis, with cracks growing across them. This orientation will be relevant to aircraft applications, but it results in cracks growing across widely varying residual stress fields, accompanied by changes in microstructure and hardness. A conventional constant load range fatigue crack growth test will therefore not exhibit similitude, as crack tips at different values of stress intensity range $\Delta \mathrm{K}$ will be subject to different crack tip conditions. Therefore additional testing was performed in which the $\Delta \mathrm{K}$ was maintained constant with crack length, allowing the effect of changes in residual stress and microstructure on crack growth rates at a constant value of $\Delta \mathrm{K}$ to be determined. A selection of the data gathered on the welded samples which illustrate the influence of residual stress follows.

\section{Effect of Residual Stress on Fatigue Crack Growth Rates in Welds}

Figure 14 compares fatigue crack growth rates for VPPA welded 2024-T4 with those of parent plate. Data for the welded samples is at $\mathrm{R}$ values of 0.1 and 0.6 , and shows that there is little effect of tensile mean stress in the presence of tensile residual stresses, and second, that crack growth rates in the welded samples are accelerated with respect to the parent plate by a factor of up to a factor of 10 . Tests conducted at a constant value of $\Delta \mathrm{K}=6 \mathrm{MPam}^{1 / 2}$ confirm that the acceleration is maintained at approximately this level up to $25 \mathrm{~mm}$ from the weld line.

The dramatic influence of residual stress on weld crack growth rates is further illustrated by a comparison of growth rates produced in constant $\Delta \mathrm{K}=6 \mathrm{MPa} \mathrm{m}^{1 / 2}$ in the $\mathrm{M}(\mathrm{T})$ panels and in the CT samples.

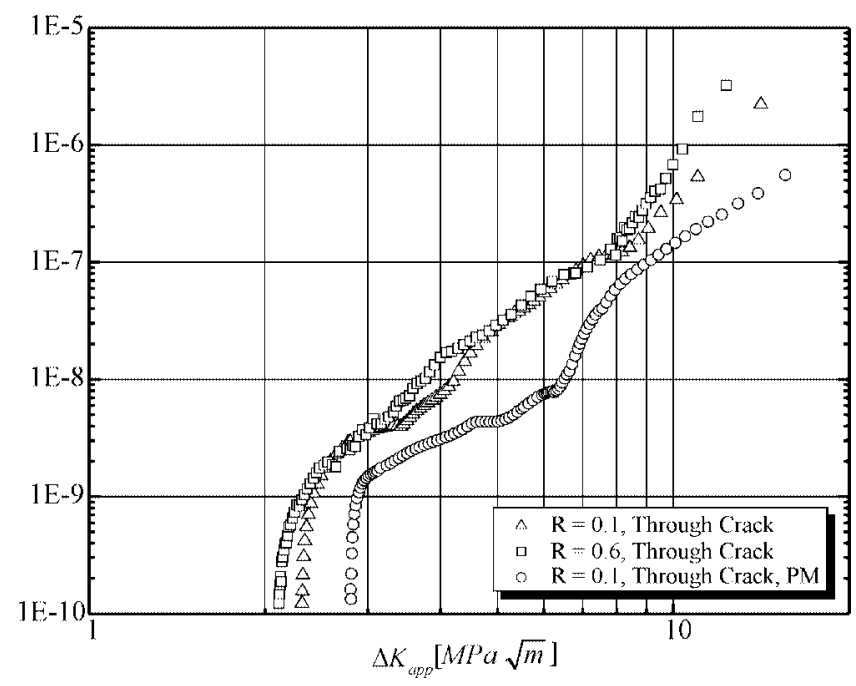

FIG. 14-da/dN vs $\Delta \mathrm{K}$ for VPPA welded 2024-T4, tested at $\mathrm{R}=0.1$ and 0.6 in $M(T)$ samples with $2 \mathrm{~mm}$ starting defect in center of the weld line. Comparison with parent plate at $\mathrm{R}=0.1$ 


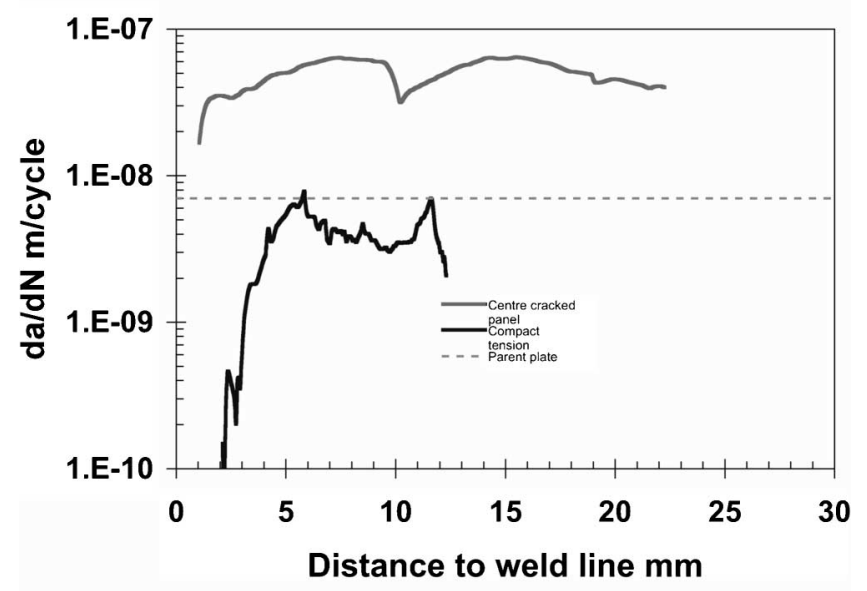

FIG. 15-Comparison of growth rates measured in CT and M(T) samples of 2024-T4 with identical VPPA welds at a constant $\square K$ of $6 \mathrm{MPa}-\mathrm{m}^{1 / 2}, \mathrm{R}=0.1$.

This is shown in Fig. 15; $\mathrm{M}(\mathrm{T})$ panels, as shown in Fig. 7, produce substantial tensile residual stresses on the weld line, whereas CT samples, a shown in Fig. 8, possess a compressive residual stress on the weld line. The growth rates in the tension residual stress field vary between $2 \times 10^{-8}$ and $7 \times 10^{-8} \mathrm{~m} /$ cycle, depending on distance from the weld line, whereas in the compact tension samples, growth rates declined to less than $10^{-10} \mathrm{~m} /$ cycle as the crack approached the weld line, and at a maximum only achieved 7 $\times 10^{-9} \mathrm{~m} /$ cycle $-\mathrm{a}$ factor of 10 slower than that in the $\mathrm{M}(\mathrm{T})$ sample with an identical weld. 7 $\times 10^{-9} \mathrm{~m} /$ cycle is the parent plate $\mathrm{da} / \mathrm{dN}$ for a $\Delta \mathrm{K}$ value of $6 \mathrm{MPa} \mathrm{m}^{1 / 2}$. As the welds in the two samples were virtually identical, the differences in growth rate must be due to residual stresses arising from welding and modified by the sample preparation processes.

Fatigue crack growth rates produced on testing the 2024-T4 skin-stringer panel with a defect introduced on the weld line were similar to those measured in the much smaller center cracked panel, when compared on the basis of stress intensity factor. Figure 16 shows da/dN versus $\Delta \mathrm{K}$ for crack growth rate measured on the 2024-T4 skin-stringer panel and those measured on the center cracked panel. There is only a small overlap in the two sets of data, but the linkup is smooth with only a little scatter. This is perhaps surprising in view of the differences in residual stresses in the two samples; however, in both cases the stresses are tensile, and the crack is originating within the weld line in both samples. The CT samples demonstrate more profound changes in growth rate when the residual stresses are compressive.

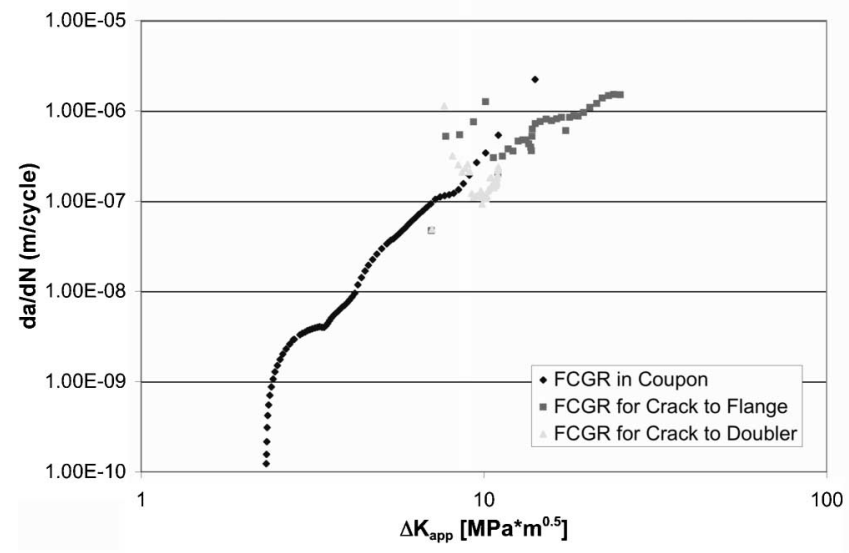

FIG. 16-Comparative fatigue crack growth rates in the skin stringer panel and the MT long crack growth specimens. 

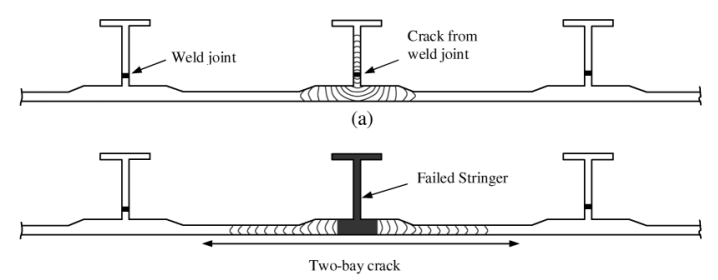

(b)

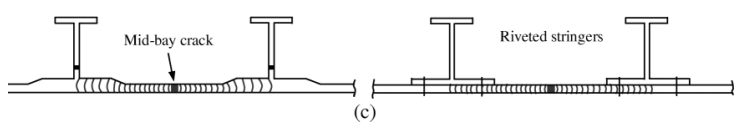

FIG. 17-Failure scenarios: (a) Stringer failure due to flaws in weld join; (b) cracking under a broken stringer; (c) midbay skin cracks from a discrete damage source, maintenance-holes, or connection fastener holes to the ribs.

\section{Implications for the Design, Fail Safety and Damage Tolerance of Aircraft Wing Panels}

The main objectives of this work are to develop analysis approaches to predict fatigue crack growth that include the influence of welding residual stress and to explore fail-safety design options for integral/ welded stringer panels. A global-local approach combining linear elastic fracture mechanics (LEFM) with the finite element method (FEM) has been employed to investigate the influence of the measured residual stress fields and fatigue crack growth rates on the design of putative welded aircraft wing structures. Initial work performed included the design of the welded skin-stringer panels for fatigue testing, crack growth analysis of the CCT specimens, and fail-safety and damage tolerance analysis of welded stringer panels. Due to space constraints only some conclusions of the latter two studies will be reported here. The main function of this section is to illustrate how the residual stress measurements can be included in a holistic design model of the damage tolerance of welded aircraft structures. Details of fail-safety (residual strength) and damage tolerance analysis (fatigue crack growth and inspection) can be found in [20].

\section{Design of Two-Stringer Welded Wing Skin Panels for Fatigue Testing}

The design constraints (decided by the WELDES consortium) were that the weld joint in the stringer should be in the web close to the skin panel and the thickness of all weld samples are $7 \mathrm{~mm}$ (after post-weld machining). In addition, the panel had to be capable of being tested in the available $1 \mathrm{MN}$ fatigue-testing machine. An "I" section was adopted to represent the wing's lower covers, in order to make comparisons with similar built-up designs. The final design configuration was shown in Fig. 9(a). The stringer to skin area ratio $\left(\mathrm{A}_{\mathrm{st}} / \mathrm{bt}\right)$ is defined as the ratio of the stiffener cross-section area $\left(\mathrm{A}_{\mathrm{st}}\right)$ to the product of the bay width (b) and skin thickness $(\mathrm{t})$. It is 1.03 for the tension panel.

\section{Damage Tolerance and Fail-Safety Analysis of Welded Stringer Panels}

Welded stringer panels behave like integrally machined panels; both are unitized structures without redundancy structural members. In contrast, the mechanically fastened (built-up) panels are desirable in terms of fail-safety criterion since the stringers are effective crack stoppers. However, the integral and welded panels are becoming increasingly popular due to much reduced manufacturing cost and considerable weight savings. It is necessary and timely to investigate the fail-safety and damage tolerance aspects of this kind of stringer panel.

The first failure scenario considered was crack initiation and subsequent propagation from the weld joint at the stringer web [Fig. 17(a)]. The welded joint has high tensile residual stresses and local microstructural change resulting in lower fatigue strength (crack initiation aspect) and faster crack growth rate (crack propagation aspect). Another important failure mode is a crack propagating in the panel skin, e.g., crack under a broken stringer in Fig. 17(b) and a midbay skin crack in Fig. 17(c).

For built-up panels the bolted stringers act as effective crack stoppers to arrest these cracks. However, the welded or integral stringers are not so effective; they will slow down the crack growth rate as the crack tip approaches an integral stringer due to the integral fastening system being completely rigid hence reducing the stress intensity factor $(\mathrm{K})$, but these stringers will not act as crack stoppers. Analyses were performed for both damage tolerance (crack growth life) and fail-safety (residual strength and large crack 


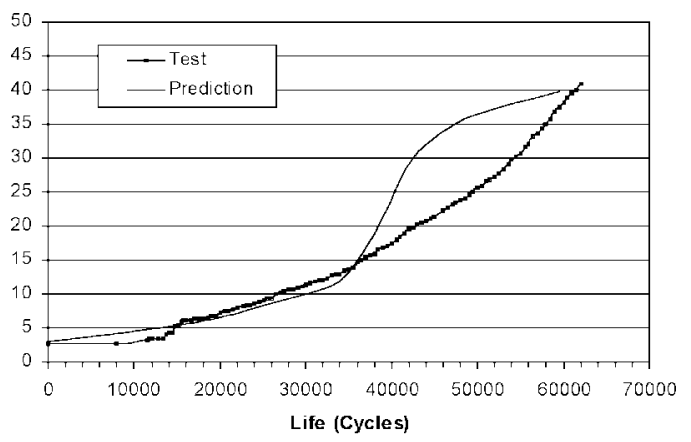

(a)

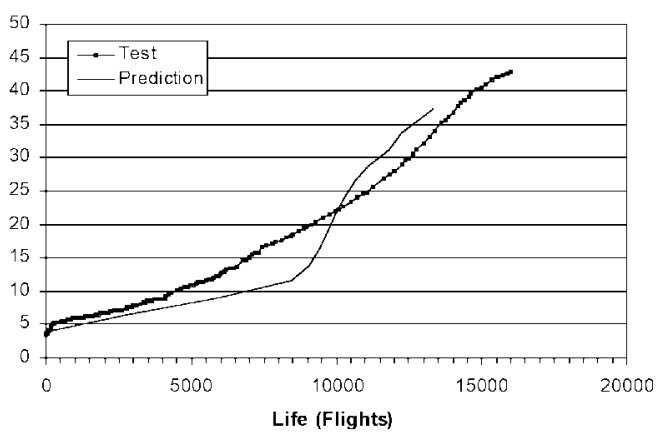

(b)

FIG. 18-Stringer web cracking from the weld joint-predicted fatigue crack growth life and comparison with test results. (a) Tension panel under $C A L\left(\mathrm{~S}_{\max }=88 \mathrm{MPa}, \mathrm{R}=0.1\right) ;(b)$ tension panel under aircraft service load spectrum $\left(\mathrm{S}_{\max }=138 \mathrm{MPa}\right)$.

capability) aspects. The stress intensity factor $(\mathrm{K})$ versus crack length relation for the skin-stringer panels was established by finite element analysis (FEA). FEA was then used to calculate crack closure induced changes to derive $\triangle \mathrm{K}_{\text {eff }}$, taking into account extra plasticity effects arising from local softening in the HAZ and weld residual stress effects. In this first approach, crack opening stress is assumed to be a function of the stress ratio $(R)$ and welding residual stress and not related to geometry. For a given structure, once the $\triangle K$ and the crack opening stress are found, fatigue life prediction was carried out for a given load spectrum using the AFGROW software package. This approach works well for the constant amplitude loading cases. For variable amplitude loads, an alternative approach was used. The welding residual stress distribution was simply input into the AFGROW code that calculates the residual stress intensity factor by either GAUSSIAN integration or weight function methods and then predicts fatigue crack growth life. Life prediction by both methods is demonstrated below.

\section{Life Prediction Results}

For the two-stringer panel, we assumed that one stringer has a defect at the weld joint with the total length of $6 \mathrm{~mm}$. This flaw could be caused by fatigue process and the local residual tensile stresses or an initial weld defect. So this is a real threat to welded structural panels under the damage tolerance design concept. The crack is supposed to grow simultaneously toward the stringer upper flange and the skin doubler. This was simulated by moving the two crack tips in both directions simultaneously. The virtual crack closure technique (VCCT) was used to calculate the strain energy release rate that was then converted to a stress intensity factor (SIF). Figure 18 shows the life prediction results under constant amplitude and aircraft service loading spectra, respectively. The agreement with the test results is reasonably good for this complex problem. Further work is necessary to address the effect of residual stress relaxation and redistribution owing to crack growth. This may improve the accuracy of life prediction.

\section{Conclusions}

The WELDES project has uniquely integrated the powerful recent developments in non-destructive residual stress measurement using neutron and synchrotron X-ray diffraction with the damage tolerance data 
acquisition and design necessary to implement welded aircraft structures. Significant new knowledge has been obtained and a mechanism for dealing with the loss of similitude that occurs when residual stresses are present in structures has been developed. It is shown that if accurate reliable residual stress data is available then adequate predictions of the fatigue life of welded structures can be made.

\section{References}

[1] Heinz, A., Haszler, A., Keidel, C., Moldenaur, S., Benedictus, R., and Miller, W. S., "Recent Developments in Aluminium Alloys for Aerospace Applications," Mater. Sci. Eng., A 280(2), 102-107 (2000).

[2] Fitzpatrick, M. E. and Edwards, L., "Fatigue Crack/Residual Stress Field Interactions and Their Implications for Damage-Tolerant Design," J. Mater. Eng. Perform. 7(2), 190-198 (1998).

[3] Mendez, P. F., "New Trends in Welding in the Aeronautic Industry," Proceedings of the Conference "New Trends for the Manufacturing in the Aeronautic Industry," Publ. Hegan/Inasmet, San Sebastian, Spain, 2000.

[4] Angus, W. Thomas, "Parameter Development for the Mig Weldings of High Strength Aerospace Aluminium Alloys," Ph.D thesis, School of Industrial and Manufacturing Science Cranfield University, 2002.

[5] Nunes, A. C., Bayless, E. O., Jones, C. S., Munafo, P. M., Biddle, A. P., Wilson, W. A., Nuflez, A. C., and Bayless, E. O., "Variable Polarity Plasma Arc Welding on the Space Shuttle External Tank," Weld. J. (Miami, FL, U. S.) 63(9), 27-35 (1984).

[6] Woodward, H., "International Space Station-Welding Will Be Out of This world," Weld. J. (Miami, FL, U. S.) 75(3), 34-40 (1996).

[7] Withers, P. J. and Webster, P. J., "Neutron and Synchrotron Strain Scanning," Strain 37(1), 19-25 (2001).

[8] ISO/TTA 3:200I, "Polycrystalline Materials—Determination of Residual Stresses by Neutron Diffraction."

[9] Stelmukh, V., Edwards, L., Santisteban, J. R., Ganguly, S., and Fitzpatrick, M. E., "Weld Stress Mapping Using Neutron and Synchrotron X-Ray Diffraction," Mater. Sci. Forum 404-407, 599-604 (2002).

[10] Daymond, M. R. and Edwards, L., "A Fully Refined Diffractometer Designed Specifically for the Measurement of Stress," Neutron News 15, 24-29 (2004).

[11] Stelmukh, V., Edwards, L., and Ganguly, S., "Full Stress Tensor Determination in a Textured Aerospace Aluminium Alloy Plate Using Synchrotron X-Ray Diffraction," Textures Microstruct. 35(3-4), 175-183 (2003).

[12] Zhang, Y., Fitzpatrick, M. E., and Edwards, L., "Cross-Sectional Mapping of Residual Stresses in a VPPA Weld Using the Contour Method," Acta Mater. 52(17), 5225-5232 (2004).

[13] Stelmukh, V. and Edwards, L., "Optimizing Neutron Strain Scanning by the Use of Electron Backscatter Diffraction," Microscopy and Analysis 91, 2002, pp. 15-18.

[14] Ganguly, S., Fitzpatrick, M. E., and Edwards, L., "Use of Neutron and Synchrotron X-ray Diffraction for Non-destructive Evaluation of Weld Residual Stresses in Aluminium Alloys," J. Neutron Res. 11, 219-225 (2004).

[15] Ganguly, S., Fitzpatrick, M. E., and Edwards, L., "Comparative Neutron and Synchrotron X-Ray Diffraction Studies to Determine Residual Stress on an As-Welded AA2024 Plate," Mater. Sci. Forum 490, 223-228 (2005).

[16] Pratihar, S., Stelmukh, V., Hutchings, M. T., Fitzpatrick, M. E., Stuwe, U., and Edwards, L., "Measurement of the Residual Stress in MIG Welded 2024-T351 and 7150-T651 Compact Tension Samples," Mater. Sci. Eng. to be published.

[17] Lefebvre, F., Ganguly, S., and Sinclair, I., "Micromechanical Aspects of Fatigue in a MIG Welded Aluminium Airframe Alloy," Mater. Sci. Eng., A 397, 338-354 (2005).

[18] Edwards, L. and Zhang, Y. H., "Investigation of Small Fatigue Cracks. II. A Plasticity Based Model of Small Fatigue Crack Growth," Acta Metall. Mater. 42(4), 1423-1431 (1994). 
[19] Hünecke, J. and Schöne, D., "Short Crack Behaviour in a Low Carbon Steel under Fatigue Loading," Proc Fatigue 2002, edited by A. F. Blom, ISBN 19015372853, 2002, pp. 2021-2028.

[20] Zhang, X. and Li, Y., "Damage Tolerance and Fail Safety of Welded Aircraft Wing Panels," AIAA J. 43(7), 1613-1623 (2005). 